\title{
Impact of Public Announcements on Stock Prices: the Example of Lithuanian Stock Market Considering Values of Stock Prices
}

\author{
Jurgita Stankevičiene' ${ }^{1}$, Simas Akelaitis ${ }^{2},{ }^{1,2}$ Kaunas University of Technology
}

\begin{abstract}
The previous studies have shown that there is a relation between values of stock prices and the price changes caused by public announcements. Thus the aim of this paper is to examine if the respective relation can be observed in Lithuanian stock market and how it is affected by different categories of announcements. A simplified version of the event study methodology was used in this paper and the average absolute and abnormal returns were calculated. A negative correlation between the values of stock prices and the price changes caused by public announcements was observed; that is consistent with the previous studies.
\end{abstract}

Keywords-Abnormal returns, Lithuanian stock market, public announcements, stock prices.

\section{INTRODUCTION}

According to Fama on an efficient market, the stock prices should fully reflect all the information that is available to potential investors. Bearing in mind the fact that the main source of new information about any company gained by the concerned parties usually are the public announcements which companies deliver in various ways, the stock prices on an efficient market should react directly to all the new information announced by companies [6], [7]. However, a growing amount of studies show that the activity of financial markets reflected by movements of stock prices does not always comply with the Efficient Market Hypothesis as determined by Fama [6]. While the results of some studies show that stock markets overreact to news [2], [15], [1], the others observed an underreaction [21], [7], [11]. Thus in many cases the role of information in stock markets could not be determined as unambiguous.

In order to measure the impact of public information on the stock markets, two indicators were used in previous studies: the stock prices and the trading volumes. Since the price movements reflect changes in the market's consensus expectations generated by a news release [20], [3], and this general perception is considered to be more appropriate for our research, thus in this paper we focus on price changes.

There is an extensive literature examining the reflection of public information in the stock prices. During the last decades, the information content of news and the capital market efficiency was tested by focusing on how the market reacts to different public announcements, issued by companies and perceived by investors, including such categories as takeover announcements, shareholder details, periodic reports, asset acquisitions and disposals, dividend announcements, progress reports, management of a company and the like. However, it must be noted that the main emphasis in the respective studies is being put on the categories of public announcements (with all the new financial information-annual, semi-annual, quarterly, monthly, etc., earnings announcements, forecasts of earnings, analysts' ratings and other financial information - as the most popular category), as well as on the types of announcements (it is quite common to classify the announcements as "good" and "bad"). Meanwhile the relationship between the value of the stock price itself and the price changes is being analyzed only by a few authors. The most remarkable of such studies was carried out by [19] whose insights have a great importance in this paper. Thus the main purpose of this paper is to evaluate the relationship between the value of stock prices in Lithuanian stock market and stock price changes determined by public announcements in the context of different categories and types of announcements.

Vilnius Stock Exchange (SE) was selected for this research namely for two reasons. Firstly, the respective studies are mainly focused on the developed stock markets (e.g., USA) while less developed stock markets (like Vilnius SE) has been analyzed only by few. Secondly, Lithuanian stock market has been defined as having the semi-strong form of efficiency; this suggests that there is a probability to get profit from the inefficiencies [8]. Thus a respective research could have a practical applicability for investors (see a brief literature review, concerning the studies of Lithuanian stock market in Table I).

TABLE I

The Previous STUdies, CONCERNing LithuANiAn Stock Market

\begin{tabular}{|l|l|c|}
\hline \multicolumn{1}{|c|}{$\begin{array}{c}\text { Author(s), } \\
\text { year }\end{array}$} & \multicolumn{1}{|c|}{ Title of the article } & $\begin{array}{c}\text { The examined } \\
\text { period }\end{array}$ \\
\hline $\begin{array}{l}\text { Eizentas, } \\
\text { Krušinskas, } \\
\text { Stankevičienè } \\
(2012)\end{array}$ & $\begin{array}{l}\text { Impact of public information signals on share } \\
\text { prices: evidence from Lithuania }\end{array}$ & $2005-2009$ \\
\hline $\begin{array}{l}\text { Kiete, Uloza } \\
(2005\end{array}$ & $\begin{array}{l}\text { The information efficiency of the stock markets } \\
\text { in Lithuania and Latvia }\end{array}$ & $2001-2004$ \\
\hline $\begin{array}{l}\text { Laidroo, } \\
\text { Grigaliūnienė } \\
(2012)\end{array}$ & $\begin{array}{l}\text { Testing for asymmetries in price reactions to } \\
\text { quarterly earnings announcements on Tallinn, } \\
\text { Riga and Vilnius Stock Exchanges during 2000- } \\
\text { 2009 }\end{array}$ & $2000-2009$ \\
\hline $\begin{array}{l}\text { Laidroo } \\
(2008)\end{array}$ & $\begin{array}{l}\text { Public announcement induced market reaction } \\
\text { on Baltic stock exchanges }\end{array}$ & $2001-2005$ \\
\hline
\end{tabular}


Eizentas et al. used an absolute return of stock in the research of impact of information signals on the stock market prices of the companies listed in the NASDAQ OMX Vilnius SE and the results have shown that there were a few categories of announcements that caused significant changes of the stock prices [5]. Kiete and Uloza used the Patell's Standardized Residual Test, the Standardized Cross-Sectional Model and the Cumulative Abnormal Returns method and the findings of their research have shown that the Lithuanian market is in a semi-strong form of efficiency; thus financial brokerages have many opportunities to exploit inefficiencies [8]. Laidroo and Grigaliūnienè investigated the asymmetries in the stock price reactions to the announcements of quarterly earnings and the results have shown that the reaction to positive news is higher than to the negative news [10]. All of the studies have shown that there are some inefficiencies in the Lithuanian stock market that could be exploited by investors in order to gain profit, however none of them was based on the relationship between values of the stock prices and price changes caused by public announcements, which might show some inefficiencies as well.

\section{THE IMPACT OF PUBLIC ANNOUNCEMENTS ON THE STOCK PRICES}

There is an extensive literature examining the impact of different categories of public announcements on stock markets further we provide a brief insight on the relevant past studies based on the relationship between stock markets and public announcements.

Palmon and Schneller carried out an in-depth research on the relationship of stock prices and public announcements. The authors examined 29 categories of announcements which were divided according to their sentiment into "bad" news and "good" news. The results of the respective research were inconsistent with the Efficient Market Hypothesis: in many cases stock price changes were not explained by the announced information that was supposed to be new to investors [13].

Morse carried out the research on the relationship between the stock prices and public announcements by examining 9 different categories of announcements [12]. The results of the research suggested that the information disclosed in public announcements reached investors faster than it was released in a public source examined by the author ("Wall Street Journal"). It was observed that stock markets react to all of the 9 determined categories of announcements, which have an impact on both - the stock prices and trading volumes; the greatest impact was made by the announcements related to the financial information.

Ryan and Taffler examined the impact of 32 different categories of announcements on stock prices and trading volumes [16]. The results of this research have shown that different categories of announcements have different impact on stock prices. Moreover, it was observed that only a few of the determined announcements' categories had a significant impact on stock prices and trading volumes; analysts' recommendations and earnings forecast revisions were observed as the categories of announcements having the greatest effect. It was estimated that analysts' recommendations explain $17.4 \%$ of "explained" price changes and $16.1 \%$ of "explained" trading volume movements.

The research of Vega distinguishes by many aspects. She separated the public announcements from private announcements, and what is more, she analyzed the relationship between public announcements and stock price movements in different price ranges as well [19]. An interesting finding of the research was that the more information investors have about the true value of an asset and the more they agree and trade on this information, the less is the impact of the announced respective information on stock prices.

According to Pritamani and Singal, the type of news is of great importance when determining the relationship between public announcements and stock price changes. The authors divided all of the announcements into 7 categories according to their content [14].

Sprenger and Welpe analyzed the impact of public announcements on stock prices in six main categories. The authors also separated the positive and negative announcements as they were expected to have different impact on stock prices. In addition to that, these authors stated that the category of announcements also plays a significant role in the respective relationship and their results evidenced that some categories of announcements make a great impact on stock prices' movements while there are some that have little to none impact [18].

Based on the previous studies all public announcements may be classified into 6 categories (see Table II).

\section{TABLE II}

CATEGORIES OF PUBlic ANNOUNCEMENTS

\begin{tabular}{|l|l|}
\hline Main category & \multicolumn{1}{|c|}{ Sub-categories } \\
\hline Positive financials & $\begin{array}{l}\text { Periodical announcements, concerning the increase of } \\
\text { revenues or profits, positive analysts' reports, positive } \\
\text { financial forecasts, etc. }\end{array}$ \\
\hline Negative financials & $\begin{array}{l}\text { Periodical announcements, concerning the decline of } \\
\text { revenues or increase of losses, negative analysts' reports, } \\
\text { negative financial forecasts, etc. }\end{array}$ \\
\hline Other financials & $\begin{array}{l}\text { Annual report; periodical report, financing; financial } \\
\text { costs/revenues, forecasts of financial results, etc. }\end{array}$ \\
\hline $\begin{array}{l}\text { Restructuring and } \\
\text { management- } \\
\text { related }\end{array}$ & $\begin{array}{l}\text { Changes in auditors, changes in management board, } \\
\text { changes in supervisory council, options granted to } \\
\text { employees, etc. }\end{array}$ \\
\hline Insider transactions & $\begin{array}{l}\text { Notifications on transactions concluded by managers of the } \\
\text { companies, notifications concerning insider trading, etc. }\end{array}$ \\
\hline Meetings of \\
shareholders
\end{tabular}$\quad$\begin{tabular}{l}
$\begin{array}{l}\text { Shareholders' agreements, annual general meeting agenda, } \\
\text { extraordinary general meeting agenda, annual general } \\
\text { meeting decisions, extraordinary general meeting } \\
\text { decisions, etc. }\end{array}$ \\
\hline
\end{tabular}

Not all of the categories had equal weight in the total number of public announcements issued in Vilnius SE, however, an assumption was made that the results are significant if the category consists of at least $1 \%$ of all the announcements issued in Vilnius SE in the respective period (which is equal to 130 announcements). It was estimated that all of the respective categories of announcements met this requirement of quantity. 


\section{RESEARCH METHODS}

The most commonly used technique for testing the interaction between the public announcements and the stock price changes is the event study methodology. Due to the resemblance of this research to the one carried out by Ryan and Taffler, the event study methodology used in this paper was based on the one suggested by the mentioned authors [16]. According to this methodology, each new information signal announced by a particular company in the Stock Exchange is estimated by replacing the calendar date into an event date and this event date is treated as the date of the public announcement. The 13 day window was selected due to the desire to explore reactions of the investors in the short term; the probability of the distortion of the results caused by non-trading days being included in the event lag was taken into consideration as well. In order to eliminate this distortion, criteria which must be met by a public announcement included in the research were set - every event lag of $[-6 ;+6]$ days had to contain only one public announcement (or a few public announcements in the case they could be attributed to the same category).

In order to evaluate the stock price changes determined by public announcements, the average absolute return and abnormal return were estimated. Average absolute return was calculated as an arithmetic mean of all the returns of stocks after the respective new one was announced. However the average absolute return does not eliminate the effect of the market. Thus abnormal return (AR) was calculated as suggested by Sprenger and Welpe (2001):

$$
A R_{i}=R_{i}-E\left(R_{i}\right)
$$

where

$A R_{i}$ the abnormal return associated with stock of a particular company $i$ on the 7 th day;

$R_{i} \quad$ actual return for stock of a particular company $i$ on the 7th day;

$E\left(R_{i}\right)$ expected return for stock of a particular company $\mathrm{i}$ on the 7 th day.

The simple version suggested by Sprenger and Welpe, was being used in order to estimate the expected return. According to these authors the expected return was the actual return of relevant market index; NASDAQ OMXV index served for this purpose in our research. Eventually, the average abnormal return (AAR) was calculated as an arithmetic mean of AR.

The research is based on the separate calculations of average absolute and abnormal returns for respective categories of announcements (see Table II) in different stock price ranges, as well as on the sentiment of news in each category.

Three stock price ranges were defined: the lowest from 0 to 0.29 Euros; medium from 0.29 to 2.90 Euros; and the highest from 2.90 Euros to 28.96 Euros.

The period chosen for the analysis was $2005-2012$. The number of companies (whose stock price movements were observed) varied from 13 to 32 throughout the respective period (see Table III).
TABLE III

NuMBER OF COMPANIES SELECTED BY YEAR

\begin{tabular}{|l|l|l|l|l|l|l|l|l|}
\hline \multirow{2}{*}{$\begin{array}{l}\text { Range of stock } \\
\text { prices }\end{array}$} & \multicolumn{7}{|c|}{ Years } \\
\cline { 2 - 10 } & 2005 & 2006 & 2007 & 2008 & 2009 & 2010 & 2011 & 2012 \\
\hline$[0 ; 0.29]$ & 2 & 2 & 2 & 3 & 6 & 6 & 7 & 11 \\
\hline$[0.29 ; 2.90]$ & 9 & 13 & 15 & 9 & 10 & 16 & 18 & 19 \\
\hline$[2.9 ; 28.96]$ & 5 & 6 & 7 & 1 & 0 & 0 & 2 & 2 \\
\hline Total & 16 & 21 & 24 & 13 & 16 & 22 & 27 & 32 \\
\hline
\end{tabular}

The companies were assigned to the respective price range based on the last close prices of the stock. The number of companies included in this research varied due to the movements throughout the ranges during the period of one year which makes it impossible to appoint the particular company to one price range. There were some companies whose stock prices greatly fluctuated and moved between the price ranges during the research period; the stock of these companies was included in our research and was appointed to the price range accordingly. During the research period, most of the companies were attributed to the medium range of stock prices, however, there were only few to none companies whose stock was assigned to the highest price range; this was considered when significance of the results was evaluated.

The selected sample consisted of 1380 public announcements. The number of evaluated announcements in each category by ranges can be seen in Table IV.

TABLE IV

Number of Evaluated Public ANNOUNCEMENTS ACCORDING TO PRICE RANGE

\begin{tabular}{|l|c|c|c|c|}
\hline \multicolumn{1}{|c|}{ Main category } & {$[0 ; 0.29]$} & {$[0.29 ; 2.90]$} & {$[2.9 ; 28.96]$} & Total \\
\hline Insider transactions & 20 & 139 & 38 & 197 \\
\hline Meetings of shareholders & 97 & 166 & 28 & 291 \\
\hline Negative financials & 58 & 70 & 15 & 143 \\
\hline Other financials & 33 & 117 & 23 & 173 \\
\hline Positive financials & 36 & 206 & 88 & 330 \\
\hline $\begin{array}{l}\text { Restructuring and } \\
\text { management-related }\end{array}$ & 37 & 180 & 29 & 246 \\
\hline Total & 281 & 878 & 221 & 1380 \\
\hline
\end{tabular}

Most of the announcements were financial related. The number of announcement categories analyzed in each price range was based on the requirements, stated in the previous section of this paper (i.e., the total amount of the announcements in the category had to be equal to at least 130). However, the group of the announcements was eliminated from the research in a particular price range, if less than 10 announcements were observed concerning the effect (positive or negative) on a stock price. Three such cases were identified in our research: the restructuring and management related announcements in the lowest price range (there were only 8 announcements with positive effect); announcements of insider transactions in the lowest price range (there were only 5 announcements with negative effect); and negative financial announcements in the high price range (too small amount of announcements with both, positive and negative effect). 
The estimated abnormal returns were divided into "increases" (positive effect) and "declines" (negative effect) depending on the stock price movements caused by the public announcements.

\section{FINDINGS OF THE RESEARCH OF STOCK MARKETS' REACTION TO PUBLIC ANNOUNCEMENTS}

In order to find out if the price range has significant impact on the link between variation of stock prices and public announcements as was stated by Vega the research was split into three smaller parts according to the price range and thus the impact of public announcements on stock prices was examined in low, medium and high price ranges [19].

In the range of low prices four categories of announcements were examined - announcements whose content is related to meetings of shareholders, negative financial information, positive financial information and other financial information (see Fig. 1).

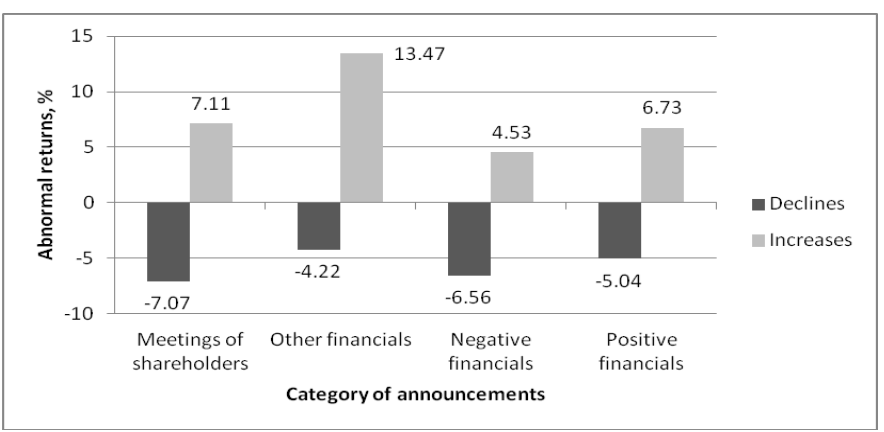

Fig. 1. Average abnormal returns in low price range.

The research evidenced that in the low prices range, announcements which were classified under the category of other financials had the strongest impact on stock prices - on average the announcement of such information caused abnormal returns equal to $13.47 \%$ if stock prices were to increase. The results are inconsistent with the previous studies which estimated that news considering financial information has the highest impact on stock prices [10], [17], [4].

We also found that the announcements related to meetings of shareholders caused higher declines $(-7.07 \%)$ than the announcements related to negative financial information $(-6.56 \%)$, as well as higher increases $(+7.11 \%)$ than the announcements related to positive financial information $(+6.73 \%)$.

All six categories of announcements were examined in the medium price range (Fig. 2), (Fig. 3).

Different results were observed in the medium price range as compared to the ones in the low price range. Overall, announcements, considering meetings of shareholders had the highest impact on stock prices - both the declines and the increases estimated for this category were highest among all the announcements.

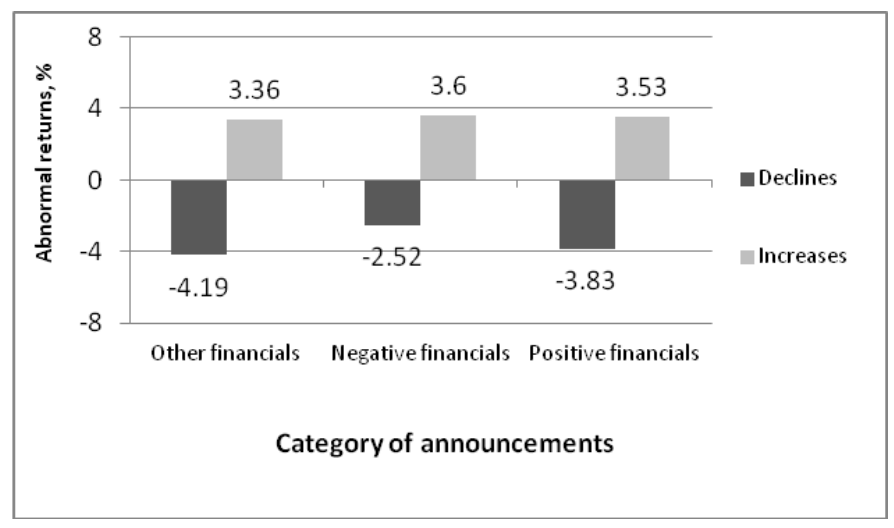

Fig. 2. Average abnormal returns in medium price range (1).

There were some other unexpected results in medium price range as well: the news considering restructuring had the least impact on stock prices among all the categories of announcements. Restructuring might have a major impact on the efficiency of a company and its profitability, thus the fact that stock prices react poorly to the release of such information might suggest that either investors are usually already aware of the respective changes or it takes longer time before the whole information of the announcements is fully reflected in the stock prices.

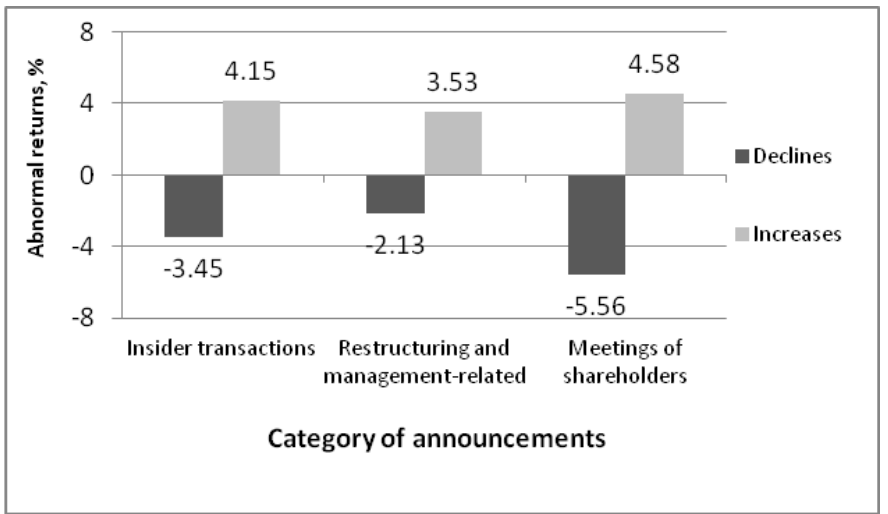

Fig. 3. Average abnormal returns in medium price range (2).

The comparison of the results in low and medium price ranges evidences that higher abnormal returns were estimated in low price range than in high price range in all the comparable categories; the highest difference was observed in the category of announcements related to other financial information (increase by $13.47 \%$ in low price range compared to increase by $3.36 \%$ in medium price range).

In the range of high prices five categories of announcements were examined: announcements considering meetings of shareholders, insider transactions, positive financial information, other financial information and restructuring and management-related announcements, as in Fig. 4 and Fig. 5. 
The results in this price range were similar to the results in other price ranges. In the range of high prices, the highest increases were observed after the news considering meetings of shareholders were announced. However, in case of declines, the highest abnormal negative returns were estimated for the category of announcements considering restructuring and management $(-3.46 \%)$.

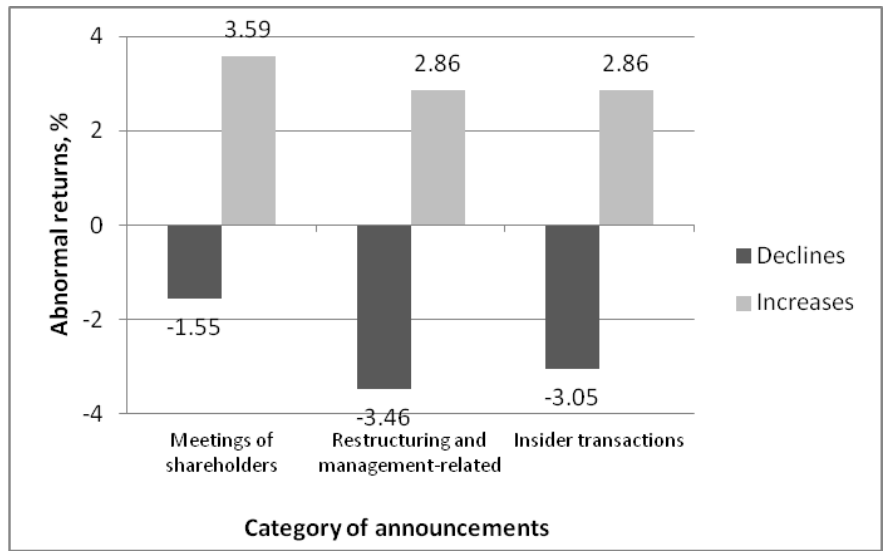

Fig. 4. Average abnormal returns in high price range (1).

In most categories (except for the category of announcements considering restructuring and management) the abnormal returns estimated in the high price range were lower than that in the medium and low price ranges. In addition to that, it can be stated that the stock prices react to the different types of the announcements in determined price ranges differently - while in most cases the highest abnormal returns were estimated for the category of announcements related to the meetings of shareholders, the variation of the rest was not tendentious. For example, extraordinary high increases $(+13.47 \%)$ were estimated for the category of announcements described as other financial information in the low price range, while in the medium and the highest price ranges, the increases estimated for this category were more comparable to the increases caused by announcements of all the other categories.

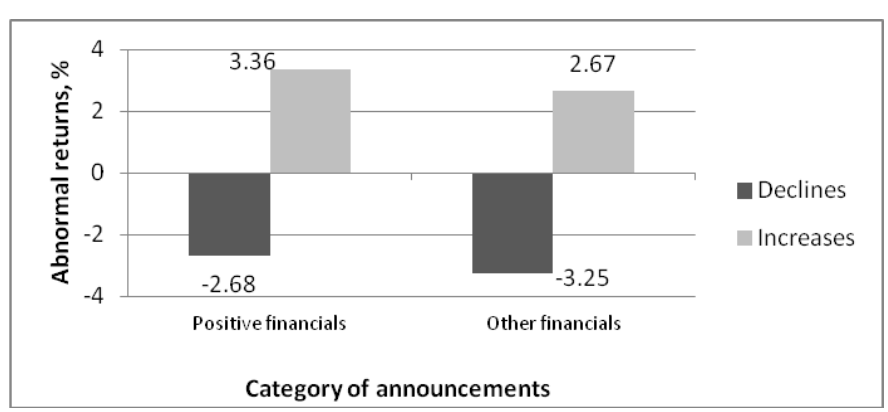

Fig. 5. Average abnormal returns in high price range (2).

The main findings of this paper are consistent with the previous studies as the impact of public announcements on the prices of stocks in the different price ranges varies notably, which means that it is purposeful to carry out further research in the respective manner [19]. The analysis based on the comparison of the average price changes in the different stock price ranges has shown that the biggest distortion of the results is related to the stock of the lowest prices. In the range of the lowest stock prices, the highest average abnormal returns were estimated for the negative financial news of the companies (the highest stock prices declines), which were equal to $-7.07 \%$, and for the other financial news (the highest stock prices increases), which were equal to $+13.47 \%$. Significantly different results were observed in the middle range of the stock prices: the lowest declines as well as the highest increases were estimated for the news concerning the general meetings of shareholders - after the respective news of positive content the stock prices increased by $+4.58 \%$ on an average, while the news of negative content caused the stock prices decline of $-5.56 \%$ on an average. The least significant activities in stock price movements were observed in the highest range of stock prices and in this range the highest negative average abnormal returns were estimated for the restructuring issues $(-3.46 \%)$ while the highest positive average abnormal returns were estimated for the news concerning the general meetings of shareholders $(+3.59 \%)$.

It must be noted that the results were consistent with the popular proposition of the previous authors (Pritamani and Singal; Ryan and Taffler) that announcements of the good content determine more remarkable stock price movements than the ones with the bad content [14], [16]. Irrespective of stock price range, the average increases of stock prices after "good" announcements estimated in this paper exceeded the mean decreases of stock prices after "bad" announcements (see Fig. 6).

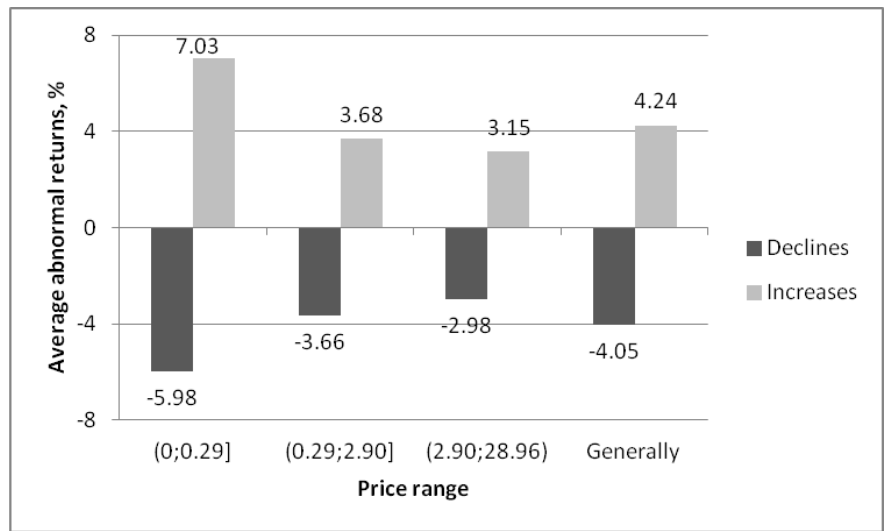

Fig. 6. Average abnormal returns in different price ranges.

Even though the findings of this research have shown obvious negative correlation between the values of stock prices and the stock price changes caused by public announcements there are some restrictions that must be taken into account. Firstly, the selected sample was relatively small and only one stock market was selected; thus the results cannot be considered as universally acceptable. Secondly, previous studies lack applicable information to determine the upper and the lower boundaries of stock price ranges. Thirdly, the simple version of model, designed to evaluate the impact of public announcements on stock prices was used. 


\section{CONCLUSION}

The main goal of this paper was to deepen the understanding of the relationship between the public announcements and changes of stock prices by analyzing the aspect which was rarely mentioned in respective previous studies - the influence of values of stock prices. Details of the relationship between the values of stock prices and stock price changes in the respective context are intriguing, as public announcements had significantly different impact on stock prices of different ranges. In addition to that, the observed relationship was fairly tendentious - the lower stock price ranges the higher abnormal returns were estimated. However, this tendency lacks universal applicability due to the restrictions; therefore it would be useful to carry out further research in the same pattern.

The results of the empirical research evidenced that the types and categories of public announcements do not play essential role when determining the relationship between values of stock prices and stock price changes as the average abnormal returns estimated for all categories, as well as for both of the types were higher in lower price ranges (with only one exception). Nevertheless, the categories and the types of public announcements did have different impact on stock prices. However this impact was not tendentious as in contrast to the effect of values of stock prices. In spite of that, higher average abnormal returns were estimated for the news of positive content than for the news of negative content (the difference varied from $0.02 \%$ to $1.05 \%$ in different price ranges) which might suggest that a more remarkable reaction of investors should be associated with a good sentiment of news. In order to testify these findings, further research on Vilnius SE should be carried out using the modified methodology (e.g., OLS regressed market model) with more extensive sample of data and possibly different stock price ranges.

\section{REFERENCES}

[1] Agrawal, A., Jaffe, J. F., Mandelker, G. N., "The Post-Merger Performance of Acquiring Firms: A Re-Examination of an Anomaly," Journal of Finance, 1992, vol. 47, pp. 1605-1621. http://dx.doi.org/10.1111/j.1540-6261.1992.tb04674.x

[2] Alwathnani, A. M., Dubofsky, D. A., "It's All Overreaction: the Post Earnings Announcement Drift," Working paper series, 2014.

[3] Beaver, W. H., "The Information Content of Annual Earnings Announcements," Journal of Accounting Research, vol. 6, 1968.

[4] Conrad, J., Cornell, B., Landsman, W. R., "When Is Bad News Really Bad News?" Journal of Finance, 2002, vol. 57, no. 6, pp. 2507-2532. http://dx.doi.org/10.1111/1540-6261.00504

[5] Eizentas, V., Krušinskas, R., Stankevičienè, J., "Impact of Public Information Signals on Share Prices: Evidence from Lithuania," Economics and Management, 2012, vol. 17, no. 3, pp. 879-888.

[6] Fama, E. F., "Efficient Capital Markets: Review of Theory and Empirical Work," The Journal of Finance, 1970, vol. 25, no. 2, pp. 383-417. http://dx.doi.org/10.2307/2325486

[7] Ikenberry, D. L., Ramnath, S., "Underreaction to Self-Selected News Events: the Case of Stock Splits," Review of Financial Studies, 2001, vol. 15, pp. 489-526. http://dx.doi.org/10.1093/rfs/15.2.489
[8] Kiete, K., Uloza, G., "The Information Efficiency of the Stock Markets in Lithuania and Latvia," SSE Riga Working Papers, 2005, vol. 75, no. 7, pp. 1-53.

[9] Laidroo, L., "Public Announcement Induced Market Reaction on Baltic Stock Exchanges," Baltic Journal of Management, 2008, vol. 3, no. 2, pp. 174-192. http://dx.doi.org/10.1108/17465260810875505

[10] Laidroo, L., Grigaliūnienè, Ž., "Asymmetries in Price Reactions to Quarterly Earnings Announcements on Tallinn, Riga and Vilnius Stock Exchanges During 2000-2009," Baltic Journal of Economics, 2011, vol. 12, no. 1, pp. 61-86. http://dx.doi.org/10.1080/1406099X.2012.10840511

[11] Michaely, R. Thaler, R. H., Womack, K. L., "Price Reactions to Dividend Initiations and Omissions: Overreaction or Drift?" Journal of Finance, 1995, vol. 50, pp. 573-608. http://dx.doi.org/10.1111/j.1540-6261.1995.tb04796.x

[12] Morse, D., "Wall Street Journal Announcements and the Securities Markets," Financial Analysts Journal, 1982, vol. 38, no. 2, pp. 69-77.

[13] Palmon, D., Schneller, M. I., "The Relationship Between Securities' Abnormal Price Movements and Wall Street Journal News," Journal of Banking and Finance, 1980, vol. 4, no. 3, pp. 235-247.

[14] Pritamani, M., Singal, V., "Return Predictability Following Large Price Changes and Information Releases," Journal of Banking \& Finance, 2001, vol. 25, pp. 631-656. http://dx.doi.org/10.1016/S0378-4266(00)00091-1

[15] Ritter, J. R., "The Long-Run Performance of Initial Public offerings," Journal of Finance, 1991, vol. 46, pp. 3-27. http://dx.doi.org/10.1111/j.1540-6261.1991.tb03743.x

[16] Ryan, P., Taffler, R. J., "Are Economically Significant Stock Returns and Trading Volumes Driven by Firm-Specific News Releases?" Journal of Business Finance \& Accounting, 2004, vol. 31, pp. 49-82. http://dx.doi.org/10.1111/j.0306-686X.2004.0002.x

[17] Skinner, D. J., Sloan, R. G., "Earnings Surprises, Growth Expectations, and Stock Returns or Don't Let an Earnings Torpedo Sink Your Portfolio," Review of Accounting Studies, 2002, vol. 7, pp. 289-312. http://dx.doi.org/10.1023/A:1020294523516

[18] Sprenger, T. O., Welpe, I. M., "News or Noise? The Stock Market Reaction to Different Types of Company-Specific News Events," Working papers series, 2011.

[19] Vega, C., "Stock Price Reaction to Public and Private Information," Journal of Financial Economics, 2006, vol. 82, issue 1, pp. 103-133. http://dx.doi.org/10.1016/j.jfineco.2005.07.011

[20] Wu, H., "Trading Volume Movement Versus Price Change: The Volume Shock Around Earning Announcement in Chinese Stock Market," Engineering Economic Management, 2013, pp. 339-345.

[21] You, H., Zhang, X. J., "Limited Attention and Stock Price Drift Following Earnings Announcements and 10-K Filings," China Finance Review International, 2011, vol. 1, issue 4, pp. 358-387. http://dx.doi.org/10.1108/20441391111167487

Jurgita Stankevičienė received the MBA degree from Kaunas University of Technology in 2001.

She is a Lecturer with the Department of Finance, School of Economics and Business, Kaunas University of Technology (Lithuania). She has previously worked as Manager and Chief Economist, and has been a Board Member of different business companies.

Her scientific interests include valuation of corporate governance and its decisions in the context of corporate value; impact of macro- and microeconomic environment on corporate value.

Address: K. Donelaičio g. 20, Room 228, Kaunas, LT-44239, Lithuania; Phone: +3707300561;

E-mail: jurgita.stankeviciene@ktu.lt

Simas Akelaitis received the Bachelor's degree in Economics from the Faculty of Economics and Management, Kaunas University of Technology in 2013. He is currently a postgraduate student of Finance, School of Economics and Business, Kaunas University of Technology.

He has worked as a Market Analyst in a Lithuanian company.

His fields of scientific interest include economics and management of international business, forecast of business environment, finance management. Address: K. Donelaičio g. 20, Room 218, Kaunas, LT-44239, Lithuania; Phone: +3707300561;

E-mail: simas.akelaitis@ktu.edu 